\title{
A machine for cold-rolling deformed reinforcing bars for model tests*
}

\author{
D. J. Evans and L. A. Clark \\ Contribution by F. A. Noor and J. Goodman \\ Teesside Polytechnic $\dagger$
}

The need for a suitable model reinforcement was stated several years ago ${ }^{(1)}$ and Mr Evans and Dr Clark are to be commended for starting this project. Unless the moment-curvature relationship is simulated throughout the complete range of loading, microconcrete models cannot be used to represent the behaviour of a statically indeterminate structure accurately. The relative stiffnesses of the various elements and the secondary moments in slender columns $(P-\Delta$ effects) will differ from those in the prototype.

It is rather unfortunate that the authors have shown us how to produce scaled ribbed reinforcing bars without reporting any tests of concrete specimens reinforced with these bars. The bond between the model reinforcement and microconcrete is only one of the parameters affecting the moment-curvature relationship. Size effects are also apparent in the tensile and compressive strengths of microconcrete ${ }^{(2,3)}$. If one considers bond alone, because the properties of microconcrete are different from those of normal concrete, exact scaling of the ribbed reinforcing bars does not appear to be essential. Furthermore, if the pull-out tests using the plain wire are anything to go by, the bond strength obtained with the authors' model reinforcement is likely to be below that of the prototype ribbed reinforcement.

At Teesside Polytechnic, we have taken the view that highly deformed wire and brittle microconcrete are more likely to give the desired curvature similitude. Our concrete mix has been designed to give a high bond strength whilst limiting the compressive to tensile strength ratio to above 12 . We have

\footnotetext{
*Pages 31 to 34 of $M C R 102$.

$\dagger$ Dr Noor is now at the Department of Civil Engineering, North East London Polytechnic.
}

also produced model reinforcement by rolling deformations into the surface of a mild-steel wire. It is similar in appearance to the hot-rolled high-yield reinforcing bars, but has exaggerated deformations. Figure I shows the rolls used in a small strip rolling mill, adapted for this purpose. The rolls have been developed with the help of the Department of Mechanical Engineering, who designed and fabricated the dies. The dies are held by rigid sides and a threaded shaft with a nut enables them to work under a high vertical pressure. A rib height of up to 0.14 diameter is possible with a $3 \mathrm{~mm}$ diameter mild-steel wire.

Figure II shows the various dies designed to give different rib spacings and the deformed wire produced by them can be seen in Figure III. In addition to being quite effective, the thin dies are also easier to fabricate and require less material. Other dies for deforming $2.5 \mathrm{~mm}$ and $2.0 \mathrm{~mm}$ wire have also been produced and are working well. Our method is to try the dies on an aluminium wire before hardening them by the specified heat treatment. Hot-rolling is possible with the Firth Vickers H50 steel used in the dies but, in the absence of a controlled environment, this has not been attempted. When cold-rolling,. our experience has shown that the initial surface texture of the wire has a significant effect upon the deformations produced. Various types of wire have been tried and the best results are given by a wire which has been annealed and lightly drawn to remove the surface scale.

Mr Evans and Dr Clark appear to have obtained an increase in the yield stress of their deformed wire without much reduction in ductility. Our experience is that, to obtain an adequate yield plateau, some reversal of the strain-hardening effect, by means of a 


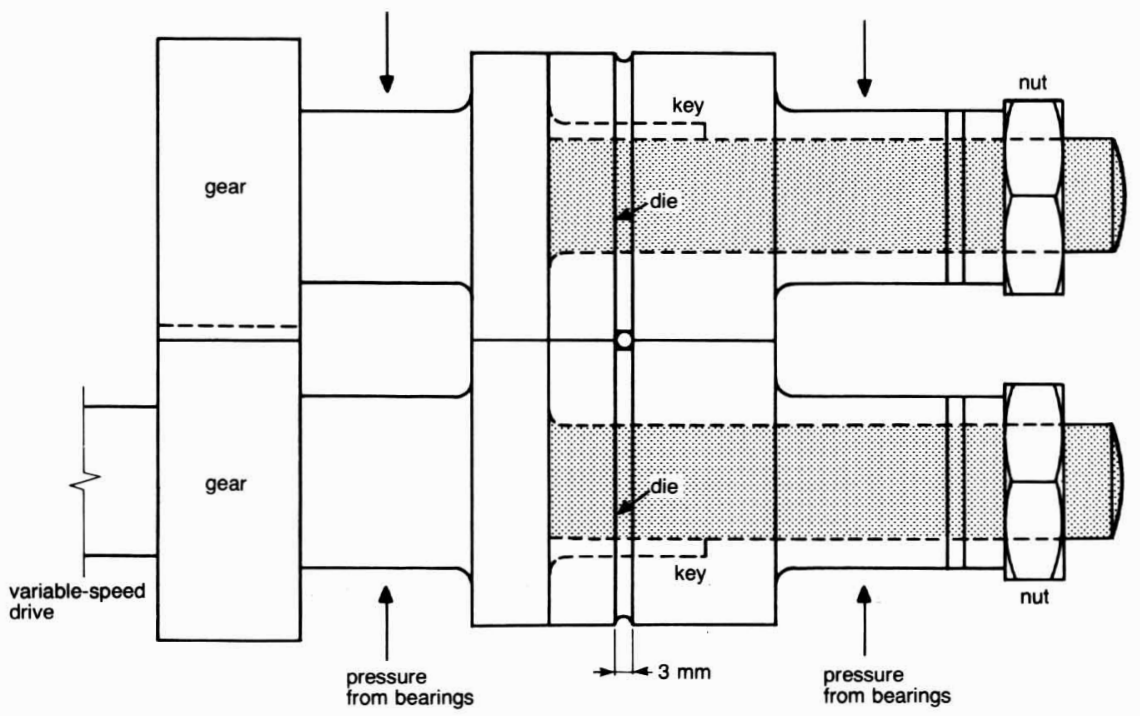

Figure I: Small strip rolling mill adapted for rolling deformations into the surface of a mild-steel wire.

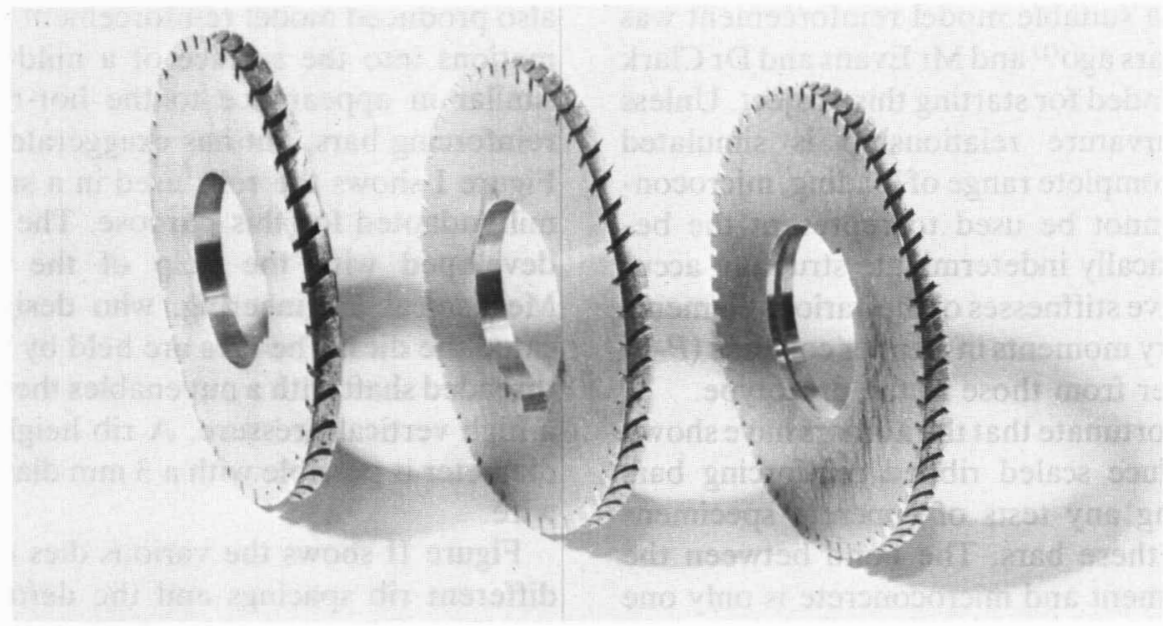

Figure II: Dies used to give different rib spacings.
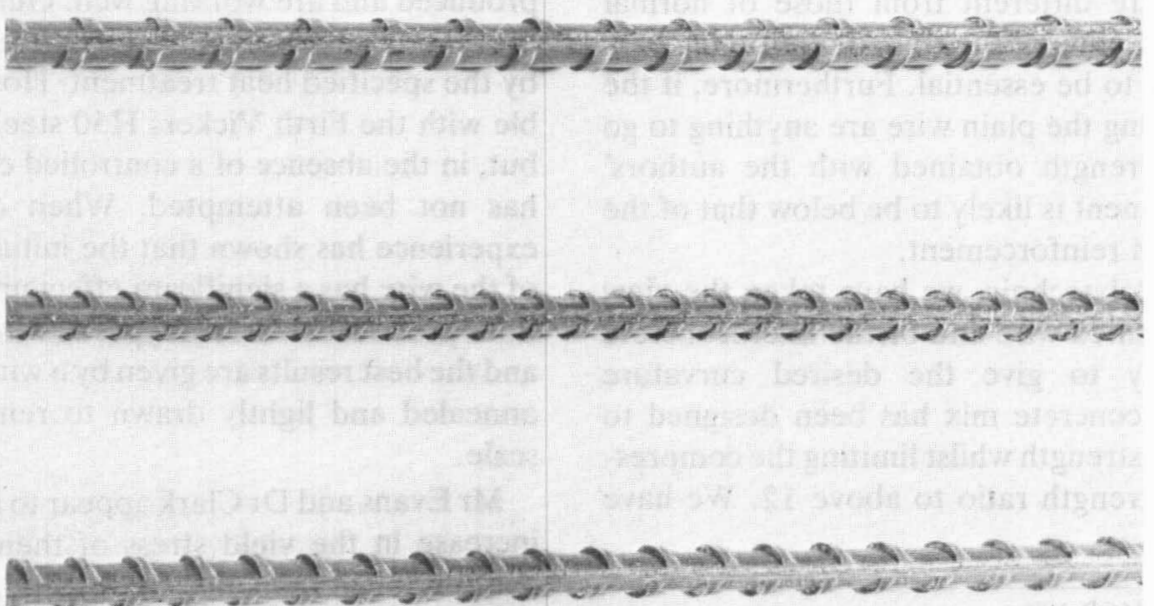

Figure III: Deformed wires produced by the three dies shown in Figure II. 
suitable heat treatment, is necessary. It has been found that, for a yield stress of $400 \mathrm{~N} / \mathrm{mm}^{2}$, the carbon content of the mild steel can be as little as $0.13 \%$. For a higher yield stress, the carbon content needs to be greater, otherwise the required ductility may not be available and the model reinforcement will fracture prematurely. The authors show a wire-straightening device in front of the rolls. Why is this necessary and would it not be more useful after the rolling process when the wire is rather curved and needs to be straightened before it can be used in a model beam?

Our deformed wire has been tried in concrete specimens such as pull-out tests and simple beams. The pull-out tests show that the average bond strength is no longer a problem and it is possible to

\section{Reply by the authors}

We thank Dr Noor and Mr Goodman for the interest that they have shown in our paper but feel that they have missed the point of the paper, which was simply to describe a machine for cold-rolling deformed reinforcing bars for model tests. The reinforcement so produced is currently being used in tests at the Cement and Concrete Association and some results of these tests were presented at the recent seminar ${ }^{(5)}$; further data will be published in due course.

We are well aware that there are size effects associated with the properties of the microconcrete and these are discussed in references 2 to 4 of the paper. We should also like to emphasize that concrete is sensitive to the strain gradient to which it is subjected, and this results in a further size effect which is discussed in references 3 and 4 of the paper. However, if too many variables affecting similitude are changed together, it is impossible to isolate their individual influences.

We share the view expressed by the discussers that exact scaling of the reinforcement may not be essential and, as we state in the paper, "testing is required to determine whether such sophisticated scaling is justified".

It is not clear to which "pull-out tests using the plain wire" the discussers refer in their second paragraph. However, our pull-out tests do indicate that model deformed reinforcement has lower ultimate average bond stresses than those of prototype have an anchorage length as short as 5 diameters. However, it is necessary to test beams before one can be sure of a satisfactory performance as regards crack spacing and deflections. The results of beams tested so far can be stated as rather encouraging because, in a number of tests, the curvatures and crack spacing have been close to those of the prototype. It appears that a much better degree of control of the materials used is necessary before consistent results are obtained. Some of the results forming the basis of the above discussion were presented at a recent research seminar ${ }^{(4)}$ and further work is now in progress. The next series of tests will include some model restrained beams with deformed and plain wire as the main and shear reinforcements, respectively.

deformed bars.

We are most interested to hear of the work on model reinforcement at Teesside Polytechnic and agree that exaggerated deformations are probably required in order to simulate post-cracking behaviour.

The probable reason why our deformed wire exhibits less reduction in ductility than that of $\mathrm{Dr}$ Noor and Mr Goodman is that ours is less heavily deformed. It is significant that, when we deform our wire heavily by knurling, a large reduction in ductility is observed (see Figure 7 of the paper).

The reason for having a wire-straightening device in front of the rolls is that our source wire is not produced especially for us and often has kinks along its length. If these were not straightened out before entering the rolls, they would cause the machine to $\mathrm{jam}$ and/or the wire to break. There is no reason why a second straightening device could not be provided after the rolling process.

Finally, we should like to state again that our reason for doing this work is that we feel that the differences observed between model and prototype behaviour are partly due to different bond failure mechanisms rather than different achievable ultimate average bond strengths. As a first step towards examining this hypothesis, it seems logical to attempt to produce a true model deformed bar with raised rib: we do not claim to have solved the problems of postcracking similitude. 


\section{REFERENCES}

1. HARRIS, H. G., SABNIS, G. M. and WHITE, R. N. Reinforcement for small scale direct models of concrete structures. Models for concrete structures. Detroit, American Concrete Institute, 1970. ACI Publication No. SP-24. pp. 141-157.

2. SABNIS, G. M. and ARONI, S. Size effects in material systems - the state of the art. Structures, Solid Mechanics and Engineering Design: Proceedings of the Southampton 1969 Civil Engineering Materials Conference. Editor: M. TE' ENI. London and New York, Wiley - Interscience, 1971. Vol. 1. pp. 131-142.

3. комLoš, к. Über den Einfluss der Querschnittsfläche auf die Festigkeits- und Verformungseigenschaften des Betons im unmittelbaren Zugversuch. (On the effect of cross-sectional area on the strength and deformation of concrete in pure tension.) Beton: Herstellung, Verwendung. Vol. 20, No. 8. August 1970. pp. 345-349.
4. NOOR, F. A. and KHALID, M. Deformed wire reinforcement for microconcrete models. Paper presented at a one-day seminar on reinforced and prestressed microconcrete models, May 1978, organized jointly by the Institution of Structural Engineers and the Building Research Establishment. Proceedings to be published.

5. WHITE, I. G. and CLARK, L. A. Bond similitude in reinforced microconcrete models. Paper presented at a one-day seminar on reinforced and prestressed microconcrete models, May 1978, jointly by the Institution of Structural Engineers and the Building Research Establishment. Proceedings to be published. 